\title{
Magnetic seizure therapy in an adolescent with refractory bipolar depression: a case report
}

\author{
This article was published in the following Dove Press journal: \\ Neuropsychiatric Disease and Treatment \\ 31 October 2014 \\ Number of times this article has been viewed
}

\author{
Yoshihiro Noda ${ }^{1,2}$ \\ Zafiris J Daskalakis ${ }^{1-3}$ \\ Jonathan Downar ${ }^{4}$ \\ Paul E Croarkin ${ }^{5}$ \\ Paul B Fitzgerald ${ }^{6}$ \\ Daniel M Blumberger ${ }^{1-3}$ \\ 'Department of Psychiatry, Faculty \\ of Medicine, University of Toronto, \\ ${ }^{2}$ Temerty Centre for Therapeutic \\ Brain Intervention, ${ }^{3}$ Campbell Family \\ Mental Health Research Institute, \\ Centre for Addiction and Mental \\ Health, ${ }^{4}$ MRI-Guided rTMS Clinic, \\ University Health Network, Toronto, \\ ON, Canada; ${ }^{5}$ Division of Child and \\ Adolescent Psychiatry, Department \\ of Psychiatry and Psychology, Mayo \\ Clinic, Rochester, MN, USA; 'Monash \\ Alfred Psychiatry Research Centre, \\ The Alfred and Monash University \\ Central Clinical School, Melbourne, \\ Australia
}

\begin{abstract}
Magnetic seizure therapy (MST) has shown efficacy in adult patients with treatmentresistant depression with limited impairment in memory. To date, the use of MST in adolescent depression has not been reported. Here we describe the first successful use of MST in the treatment of an adolescent patient with refractory bipolar depression. This patient received MST in an ongoing open-label study for treatment-resistant major depression. Treatments employed a twin-coil MST apparatus, with the center of each coil placed over the frontal cortex (ie, each coil centered over F3 and F4). MST was applied at $100 \mathrm{~Hz}$ and $100 \%$ machine output at progressively increasing train durations. Depressive symptoms were assessed using the 24-item Hamilton Depression Rating Scale and cognitive function was assessed with a comprehensive neuropsychological battery. This adolescent patient achieved full remission of clinical symptoms after an acute course of 18 MST treatments and had no apparent cognitive decline, other than some autobiographical memory impairment that may or may not be related to the MST treatment. This case report suggests that MST may be a safe and well tolerated intervention for adolescents with treatment-resistant bipolar depression. Pilot studies to further evaluate the effectiveness and safety of MST in adolescents warrant consideration.
\end{abstract}

Keywords: brain stimulation, treatment-resistant depression, adolescent depression, cognitive effects

\section{Introduction}

Major depression is a common disorder in adolescence and an important public health concern. The incidence of depression in adolescence ranges from $2.5 \%$ to $8 \%$. ${ }^{1}$ Major depression in adolescence is also associated with an increased risk of suicide, poor school performance, impaired social skills, social withdrawal, and substance abuse. ${ }^{2}$ Depressive symptoms in adolescents can be different from those in adults. In adolescent depression, symptoms are more heterogeneous and can fluctuate. Symptoms of major depression can also manifest as somatic complaints and are highly comorbid with anxiety disorders, substance abuse, disruptive behavior disorders (eg, conduct disorder and oppositional defiant disorder), personality disorders, and attention deficit disorder. ${ }^{3-6}$ Effective treatments for mild to moderate depression in adolescents may include selective serotonin reuptake inhibitors, cognitive-behavioral therapy, and interpersonal therapy. ${ }^{7}$ However, these treatments may be of limited efficacy in patients with severe symptoms. Moreover, psychotropic medications can frequently produce intolerable side effects. ${ }^{8}$ Furthermore, bipolar depression is poorly understood in youth and there is a dearth of evidence-based treatments. In general, selective serotonin reuptake inhibitors are used with caution because there are limited data to suggest these agents are effective and concern that they may induce manic episodes..$^{9,10}$ Also, recent meta-analyses showed that adolescent patients initiating therapy with a
Correspondence: Daniel M Blumberger Temerty Centre for Therapeutic Brain Intervention, Centre for Addiction and Mental Health, I00I Queen St W, Unit 4-II 5, Toronto, ON, Canada M6J IH4 $\mathrm{Tel}+\mathrm{I} 416535850 \mathrm{I}$

Fax + I 416583 I358

Email daniel.blumberger@camh.ca 
high dose of antidepressants seem to be at heightened risk of deliberate self-harm and that the efficacy of antidepressant therapy for youth seems to be modest. ${ }^{11,12}$ Further, separate evidence suggests that the antidepressant dose is generally unrelated to the therapeutic efficacy..$^{13-18}$

Electroconvulsive therapy (ECT) may be of significant benefit in adolescents who present with treatment-resistant depression. ${ }^{8}$ However, ECT is often associated with significant memory impairment and its use in adolescents with depression is still controversial. ${ }^{19}$ Repetitive transcranial magnetic stimulation (rTMS) has also been used to treat adolescent depression with very good tolerability and few adverse effects. ${ }^{20-22}$ Early evidence also suggests that treatment of resistant depression by rTMS in adolescents is not associated with long-term cognitive deterioration and that some patients may derive long-term benefit from rTMS. ${ }^{23}$ However, although rTMS is relatively well tolerated in adolescent patients with major depression, there are also reports suggesting that rTMS may not be perceived as being very helpful by patients and their parents, ${ }^{24}$ and its efficacy in adolescents has only been evaluated in a small number of open-label studies.

Magnetic seizure therapy (MST) has shown efficacy in adult patients with treatment-resistant depression without significant impairment in memory. ${ }^{25-27}$ A small randomized clinical trial of MST and ECT demonstrated equivalent antidepressant efficacy with minimal cognitive side effects in adult treatment-resistant depression. ${ }^{28}$ To date, the use of MST in adolescent depression has not been reported. Herein, we describe the first use of MST in an adolescent patient with a treatment-resistant major depressive episode in the context of bipolar II disorder who experienced full remission of depressive symptoms with no deleterious effects on memory.

\section{Materials and methods}

The current report describes the case of a patient with adolescent bipolar depression who achieved remission in an ongoing open-label study of MST (NCT01596608). The patient's diagnosis of a major depressive episode in the context of bipolar II disorder was confirmed using the SCID-IV (Structured Clinical Interviews for the Diagnostic and Statistical Manual of Mental Disorders, Fourth Edition).

In the acute treatment phase, MST was administered at a frequency of 2-3 times per week on nonconsecutive days. In the continuation treatment phase, MST was administered at a frequency of once per week for 4 weeks, one treatment every 2 weeks for 2 months, and one treatment every 3 weeks for one month, in succession. This patient had a total of $18 \mathrm{MST}$ treatment sessions in the acute treatment phase and nine treatment sessions in the continuation phase. A twin coil was used for MST (Mag Venture A/S, Farum, Denmark), and the center of each coil was placed over F3 and F4 using the 10-20 electroencephalography system. The MST determination of seizure threshold used $100 \%$ machine output applied at $100 \mathrm{~Hz}$ at progressively increasing train durations, commencing at 2 seconds and increasing by 2 seconds with each subsequent stimulation until an adequate seizure was produced. During subsequent sessions, one stimulation per session was delivered using a train duration that was 4 seconds longer than the train duration at threshold (with a maximum train duration of 10 seconds). Methohexital sodium $0.75 \mathrm{mg} / \mathrm{kg}$ and succinylcholine $0.5 \mathrm{mg} / \mathrm{kg}$ were administered for induction of anesthesia and muscle relaxation.

The primary outcome measure was remission on the 24-item version of the Hamilton Depression Rating Scale (HDRS). Remission was defined as an HDRS 24-item score $\leq 10$ and a $60 \%$ reduction in scores on two consecutive assessments, consistent with other larger convulsive therapy trials. ${ }^{29,30} \mathrm{Clinical} /$ cognitive assessments were performed by trained research analysts.

Cognition was assessed prior to and at the end of the acute treatment phase, and at 6 months post treatment. Additionally, the Montreal Cognitive Assessment was administered at baseline and every six treatments during acute treatment, and also before the first continuation treatment. It was then administered once a month during continuation treatment. The full cognitive battery included assessments of anterograde and retrograde memory, specifically looking at learning, retention, and retrieval in both the verbal and nonverbal domains. This included assessments such as the Autobiographical Memory Interview Short Form (AMI-SF), ${ }^{31}$ MATRICS Consensus Cognitive Battery, Stroop, and verbal fluency using the Controlled Oral Word Association Test (COWAT). We also evaluated general intellectual functioning through the Wechsler Test of Adult Reading prior to the start of treatment. Finally, time to reorientation was measured to assess the recovery of orientation post-MST treatment.

\section{Results}

The patient was an 18-year-old male with a first refractory major depressive episode in the context of bipolar II disorder. The depressive episode was of moderate severity without psychotic symptoms. Prior to the onset of the depressive episode, he had intentionally deprived himself of sleep to study harder. He felt he had the ability to study harder, 
stay up longer, and work harder than his classmates. After approximately 3 weeks of intentionally staying up late and sleeping only 4 hours, he developed significant depressive symptoms that continued for more than 2 months. At the onset of this depressive episode, he was evaluated and treated by a psychiatrist, and had trials of citalopram, sertraline, methylphenidate, risperidone, aripiprazole, quetiapine, and lithium during the depressive episode for 12 months. However, these antidepressants and mood stabilizers had little effect on his depressive symptoms. The patient was subsequently referred for a course of rTMS. He received bilateral dorsal medial prefrontal cortex rTMS treatment at $10 \mathrm{~Hz}, 1,500$ pulses per session ${ }^{32}$ delivered as an accelerated treatment of five sessions daily at 2-hour intervals for 5 days. ${ }^{32-34}$ Before rTMS, his 17-item HDRS score was 16 , which improved to 9 after rTMS. He had a partial response of less than $50 \%$ that was not felt to be clinically significant. His improvement was short-lived after completing rTMS, and he was referred to the Temerty Centre for Therapeutic Brain Intervention at the Centre for Addiction and Mental Health and met the eligibility criteria for the ongoing, open-label clinical trial of MST (NCT01596608).

At the time of initial assessment, his depressive episode had reached 58 weeks in duration and he was experiencing anhedonia. His energy was low and he reported poor concentration and low self-esteem. His appetite was very poor but he had not lost weight. He denied having feelings of guilt or worthlessness. However, he felt very indecisive and could not decide what to do. He had thoughts of not wanting to live but had no suicidal ideation. He denied any paranoid, persecutory, guilty, or somatic delusions. He drank alcohol only occasionally. Other than the hypomania preceding the current depressive episode, there did not appear to be any other episodes of mania or hypomania. There had been no hospitalizations or suicide attempts. He had mild hypothyroidism that was treated with thyroxine. He was euthyroid (thyroid-stimulating hormone level $3.56 \mathrm{mIU} / \mathrm{L}$ ) after thyroxine replacement therapy. There was no history of seizure, loss of consciousness, or any surgery. He did not have any metal implants in his brain.

Before starting MST treatments, both methylphenidate and lithium were tapered in consideration of the increased risk of cardiac sequelae and cognitive impairment associated with these drugs. Concomitant lithium therapy is prohibited during the MST clinical trial due to the potential for increased adverse cognitive effects when lithium is combined with ECT. ${ }^{35} \mathrm{He}$ had an acute course of 18 MST treatments over 6 weeks and nine continuation MST treatments over 6 months. During his course of MST treatments, he was on no medications other than thyroxine $0.05 \mathrm{mg}$ per day orally.

At baseline, prior to starting MST treatments, his score on the 24-item HDRS was 21 . His mean time to reorientation post-MST treatment was $29 \pm 21$ minutes. After the 12 th MST treatment, his HDRS 24-item score was reduced to 10 , and he stated that he had increased interest and wanted to return to school. In addition, he no longer demonstrated psychomotor retardation. He achieved remission after his 18th MST treatment when his HDRS 24-item score was 8. Although his processing speed and concentration improved, we continued his MST treatment according to the protocol described above as continuation MST for prevention of relapse. After his 21st MST treatment, his HDRS 24-item score ranged from three to six. His mood and energy remained good, and he continued to be physically active. Figure 1 shows the longitudinal changes in clinical outcomes measured with the 24-item HDRS.

The main results of the comprehensive neuropsychological battery at baseline and after acute and continuation treatment are reported in Table 1. Also, his average score on the Montreal Cognitive Assessment was $29 \pm 1$ points out of 30 (cut-off point is 26), suggesting that his general cognitive function was within normal limits during the entire course of MST.

The adverse effects of MST in the patient were intense nausea after the first MST treatment and multiple prolonged seizures that required termination with midazolam or extra methohexital. After MST treatment, granisetron $1 \mathrm{mg}$ or odansetron 4 mg was used to alleviate nausea at each subsequent treatment. For prolonged seizures over 150 seconds, in his acute course of MST, mean electroencephalographic and electromyographic seizures were $132 \pm 62$ seconds (on frontal EEG) and $94 \pm 42$ seconds (physical manifestation). At the acute MST 1, 3, 8, and 17 sessions, his prolonged seizures were terminated with

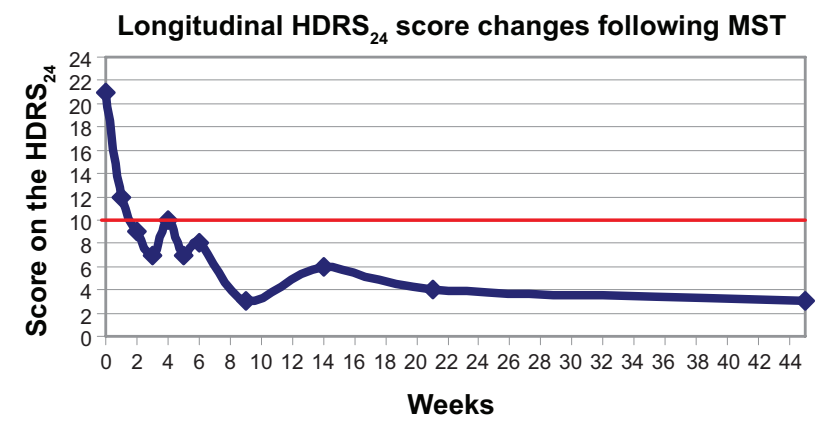

Figure I Longitudinal changes in clinical outcome measured with the $\mathrm{HDRS}_{24}$. The red line indicates the remission score cut-off point of 10 on the HDRS 24 Abbreviations: $\mathrm{HDRS}_{24}$, 24-item Hamilton Depression Rating Scale; MST, magnetic seizure therapy. 
Table I Neuropsychological battery at baseline, after acute treatment, and after continuation treatment

\begin{tabular}{|c|c|c|c|c|c|c|c|}
\hline \multicolumn{4}{|l|}{ Attention } & \multicolumn{4}{|c|}{ Executive functioning } \\
\hline \multicolumn{3}{|c|}{ Digit span (WAIS-III/WMS-III) } & Total score & \multicolumn{3}{|c|}{ Trail making test } & Time (seconds) \\
\hline \multicolumn{3}{|l|}{ Baseline } & $17 / 30$ & \multicolumn{3}{|l|}{ Baseline } & 30 \\
\hline \multicolumn{3}{|l|}{ Post } & $18 / 30$ & \multicolumn{3}{|l|}{ Post } & 23 \\
\hline \multicolumn{3}{|l|}{6 months post } & $21 / 30$ & \multicolumn{2}{|l|}{6 months post } & \multicolumn{2}{|r|}{16} \\
\hline WAIS-III Digit symbol & \multicolumn{2}{|l|}{$\operatorname{Raw}(90 s)$} & Raw (120s) & \multicolumn{2}{|l|}{ Stroop } & \multicolumn{2}{|c|}{ Number of responses } \\
\hline Baseline & \multicolumn{2}{|l|}{$57 / 133$} & $87 / 133$ & \multirow[t]{3}{*}{ Baseline } & Word score & \multicolumn{2}{|l|}{113} \\
\hline Post & \multicolumn{2}{|l|}{$49 / 133$} & $74 / 133$ & & Color task & \multicolumn{2}{|l|}{91} \\
\hline 6 months post & \multicolumn{2}{|l|}{$58 / 133$} & $81 / 133$ & & Color-word task & 61 & \\
\hline \multicolumn{3}{|l|}{ Memory functioning } & & \multirow[t]{3}{*}{ Post } & Word score & \multicolumn{2}{|l|}{102} \\
\hline CVLT recall measures & \multirow[t]{2}{*}{ Baseline } & \multirow[t]{2}{*}{ Post } & 6 months & & Color task & 82 & \\
\hline (number correct) & & & post & & Color-word task & 50 & \\
\hline List $A$ trials I-5 & $68 / 80$ & $66 / 80$ & $69 / 80$ & \multirow[t]{3}{*}{6 months post } & Word score & \multicolumn{2}{|l|}{120} \\
\hline List A trial I & $13 / 16$ & $9 / 16$ & $9 / 16$ & & Color task & 93 & \\
\hline List $A$ trial 5 & $13 / 16$ & $16 / 16$ & $16 / 16$ & & Color-word task & 44 & \\
\hline List B & $13 / 16$ & $8 / 16$ & $8 / 16$ & BVMT-R & Baseline & Post & 6 months \\
\hline List A short-delay free recall & $14 / 16$ & $15 / 16$ & $16 / 16$ & & raw score & raw score & post \\
\hline List $A$ short-delay cued recall & $14 / 16$ & $15 / 16$ & $16 / 16$ & Total recall & $29 / 36$ & $32 / 36$ & $33 / 36$ \\
\hline List A long-delay free recall & $14 / 16$ & $16 / 16$ & $15 / 16$ & Delay recall & $12 / 12$ & $11 / 12$ & $12 / 12$ \\
\hline List A long-delay cued recall & $14 / 16$ & $16 / 16$ & $15 / 16$ & Autobiograph & memory & & \\
\hline $\begin{array}{l}\text { Perseverations (free/cued } \\
\text { recall total) }\end{array}$ & 20 & 5 & 9 & AMI-SF & & & Total score \\
\hline Free recall intrusions (total) & I & I & I & Baseline & & & $52 / 60$ \\
\hline Cued recall intrusions (total) & 0 & I & । & Post & & & $35 / 60$ \\
\hline Recognition hits & $16 / 16$ & $16 / 16$ & $15 / 16$ & 6 months post & & & $35 / 60$ \\
\hline List $A$ trial 2 & $12 / 16$ & $12 / 16$ & $13 / 16$ & & & & \\
\hline List A trial 3 & $15 / 16$ & $14 / 16$ & $15 / 16$ & & & & \\
\hline List $A$ trial 4 & $15 / 16$ & $15 / 16$ & $16 / 16$ & & & & \\
\hline
\end{tabular}

Abbreviations: AMI-SF, Autobiographical Memory Interview Short Form; BVMT-R, Brief Visuospatial Memory Test-Revised; CVLT, California Verbal Learning Test; WAIS-III, Wechsler Adult Intelligence Scale, Third Edition; WMS-III, Wechsler Memory Scale, Third Edition; s, seconds.

midazolam 1-2 mg. During the continuation course of MST, mean electroencephalographic and physical seizures were $170 \pm 33$ seconds and $146 \pm 28$ seconds, respectively. During the continuation MST 2 and 6 treatments, his prolonged seizures were terminated with midazolam $2 \mathrm{mg}$ and at treatments 3,4 , 7,8 , and 9 they were terminated with methohexital $30-40 \mathrm{mg}$. The details of his are shown in Table 2.

Despite experiencing multiple prolonged seizures, he was able to return to and attend university for full-time studies following completion of the MST treatments.

\section{Discussion}

This is the first case report of an adolescent who was experiencing a treatment-resistant major depressive episode in the context of bipolar II who achieved remission of his previously refractory depression following a course of MST. His symptoms were unresponsive to several antidepressants, mood stabilizers, and augmentation therapies, and had been present for more than one year. Due to multiple psychopharmacological treatment failures, treatment with rTMS, ECT, and MST were considered as treatment options. ${ }^{27,36,37}$ After the patient

Table 2 Mean values during the acute and continuation treatment courses

\begin{tabular}{|c|c|c|c|c|c|c|c|c|c|c|c|c|}
\hline & $\begin{array}{l}\text { EEG } \\
\text { seizure } \\
\text { duration } \\
\text { (seconds) }\end{array}$ & $\begin{array}{l}\text { EMG } \\
\text { seizure } \\
\text { duration } \\
\text { (sec) }\end{array}$ & $\begin{array}{l}\text { Metho } \\
\text { hexital } \\
\text { sodium } \\
\text { (mg) }\end{array}$ & $\begin{array}{l}\text { Succinyl } \\
\text { choline } \\
\text { (mg) }\end{array}$ & $\begin{array}{l}\text { Granisetron } \\
\text { (mg) }\end{array}$ & $\begin{array}{l}\text { Ondan } \\
\text { setron } \\
\text { (mg) }\end{array}$ & $\begin{array}{l}\text { Pre- } \\
\text { HR } \\
\text { (bpm) }\end{array}$ & $\begin{array}{l}\text { Post- } \\
\text { HR } \\
\text { (bpm) }\end{array}$ & $\begin{array}{l}\text { Pre- } \\
\text { systolic } \\
\text { BP } \\
(\mathrm{mmHg})\end{array}$ & $\begin{array}{l}\text { Post- } \\
\text { systolic } \\
\text { BP } \\
(\mathrm{mmHg})\end{array}$ & $\begin{array}{l}\text { Pre- } \\
\text { diastolic } \\
\text { BP } \\
(\mathrm{mmHg})\end{array}$ & $\begin{array}{l}\text { Post- } \\
\text { diastolic } \\
\text { BP } \\
(\mathrm{mmHg})\end{array}$ \\
\hline $\begin{array}{l}\text { Acute course } \\
\text { MST }\end{array}$ & $136 \pm 62$ & $94 \pm 42$ & $62 \pm 4$ & $4 I \pm 5$ & $\mathrm{I} \pm 0$ & $4 \pm 0$ & $86 \pm 17$ & $86 \pm 16$ & $146 \pm 15$ & $161 \pm 14$ & $77 \pm 8$ & $87 \pm 15$ \\
\hline $\begin{array}{l}\text { Continuation } \\
\text { MST }\end{array}$ & $170 \pm 33$ & $146 \pm 28$ & $61 \pm 3$ & $30 \pm 0$ & $0 \pm 0$ & $4 \pm 0$ & $112 \pm 18$ & $85 \pm 13$ & $|5| \pm 4$ & $165 \pm 12$ & $80 \pm 5$ & $84 \pm 8$ \\
\hline
\end{tabular}

Abbreviations: BP, blood pressure; EEG, electroencephalographic; EMG, electromyographic; HR, heart rate; MST, magnetic seizure therapy. 
had a transient partial response to rTMS, he and his family decided to participate in our MST treatment trial.

The patient reached remission after 18 acute (ie, 2-3 times per week) MST treatments. He has maintained his remission for approximately 11 months at the time of this report. He experienced no prolonged confusion after MST treatments, consistent with a previous report. ${ }^{38}$ Finally, there was minimal subjective cognitive impairment during his MST course. He did have a reduced autobiographical memory score on testing, but this did not lead to any functional impairment.

Previous studies have reported that healthy subjects demonstrate decreased retrieval consistency in all components of the AMI-SF. For example, mean retrieval consistency in all components of the AMI-SF was approximately $80 \%$ between the initial assessment and 6 months post reassessment. ${ }^{39}$ Also, Semkovska et al proposed cut-off values defining impairment for both initial assessment and consistency in autobiographical memory retrieval after 6 months. These values were 33.5 and 23.5, respectively. ${ }^{39}$ His scores of 52 on the AMI-SF at the initial assessment and 35 at the 6 months post reassessment were within the normal range. Further, while patients with depression showed less episodic-specific autobiographical memory than healthy controls in the study by Semkovska et al both groups showed equivalent amounts of consistency loss over a 2-month interval on all components of the AMI-SF. ${ }^{39}$ Based on these findings in healthy subjects, an approximately $20 \%$ reduction in AMI-SF score can be expected between the initial assessment and 6 months post reassessment. Therefore, in this patient, we would anticipate an AMI-SF score of 42 points at 6 months post assessment compared with his actual score of 35 points. The gap between his expected 42 point (ie, 20\% reduction) and his actual 35 point (ie, $33 \%$ reduction) may be related to normal variability in performance or possibly to a mild retrograde amnesia related to MST. In the case of ECT, the evidence suggests that impairment of autobiographical memory does occur after an acute course, with effect sizes (Cohen's d) ranging from -2.69 to $-0.01 .^{40,41}$ For example, while post-ECT deficits as cognitive adverse effects were observed with the Mini-Mental State Examination, accuracy on the N-Back test, the Buschke Selective Reminding Test, and AMI-SF measures, the magnitude was substantially greater for the AMI-SF. ${ }^{29}$ Also, other studies demonstrated that loss of autobiographical memory is still present between one and 6 months after unilateral brief pulse ECT ${ }^{29,42-46}$ with large effect sizes, ${ }^{43,44}$ while ultrabrief pulse right unilateral ECT shows less decline in autobiographical memory, with nil to small effect sizes. ${ }^{29,46,47}$
In summary, our case report suggests that MST may be promising for treatment-resistant depression in adolescents. Larger studies are needed to confirm the effectiveness and safety of MST in this population.

\section{Disclosure}

In the last 5 years, DMB has received research support from the Canadian Institutes of Health Research, Brain and Behaviour Research Foundation (formerly NARSAD), the Temerty family through the Centre for Addiction and Mental Health Foundation and the Campbell Research Institute, and for an investigator-initiated study from Brainsway Ltd. ZJD received research and equipment in kind support for an investigator-initiated study through Brainsway Inc., and a travel allowance through Merck. ZJD has also received speaker funding through Sepracor Inc., and AstraZeneca, served on advisory boards for Hoffmann-La Roche Limited and Merck, and received speaker support from Eli Lilly. This work was supported by the Ontario Mental Health Foundation, the Canadian Institutes of Health Research, the Brain and Behaviour Research Foundation, and the Temerty family and Grant family through the Centre for Addiction and Mental Health Foundation and the Campbell Institute. PBF is supported by the National Health and Medical Research Council Practitioner Fellowship, and has received equipment for research from Magventure A/S, Brainsway, Medtronic, and Cervel Neurotech, and research funding from Cervel Neurotech. PEC is supported by the National Institute of Mental Health of the National Institutes of Health (K23MH100266). The content is solely the responsibility of the authors and does not necessarily represent the official views of the National Institutes of Health. PEC also receives research support from Brain and Behaviour Research Foundation Young Investigator Grant. JD receives research support from the Canadian Institutes of Health Research, the Ontario Brain Institute, the Buchan Family Foundation, and the Klarman Family Foundation, and has received in-kind equipment loans from MagVenture for research on investigator-initiated studies. YN reports no conflicts of interest in this work.

\section{References}

1. Richardson LP, Katzenellenbogen R. Childhood and adolescent depression: the role of primary care providers in diagnosis and treatment. Curr Probl Pediatr Adolesc Health Care. 2005;35(1):6-24.

2. Weller EB, Kloos A, Kang J, Weller RA. Depression in children and adolescents: does gender make a difference? Curr Psychiatry Rep. 2006;8(2):108-114

3. Renouf AG, Kovacs M, Mukerji P. Relationship of depressive, conduct, and comorbid disorders and social functioning in childhood. J Am Acad Child Adolesc Psychiatry. 1997;36(7):998-1004. 
4. Angold A, Costello EJ, Erkanli A. Comorbidity. J Child Psychol Psychiatry. 1999;40(1):57-87.

5. Small DM, Simons AD, Yovanoff P, et al. Depressed adolescents and comorbid psychiatric disorders: are there differences in the presentation of depression? J Abnorm Child Psychol. 2008;36(7): $1015-1028$.

6. Paris J. Recent research in personality disorders. Preface. Psychiatr Clin North Am. 2008;31(3):xi-xii.

7. Milin R, Walker S, Chow J. Major depressive disorder in adolescence: a brief review of the recent treatment literature. Can J Psychiatry. 2003; 48(9):600-606.

8. Rey JM, Walter G. Half a century of ECT use in young people. Am J Psychiatry. 1997;154(5):595-602.

9. Goldstein BI, Sassi R, Diler RS. Pharmacologic treatment of bipolar disorder in children and adolescents. Child Adolesc Psychiatr Clin NAm. 2012;21(4):911-939.

10. DeFilippis MS, Wagner KD. Bipolar depression in children and adolescents. CNS Spectr. 2013;18(4):209-213.

11. Jureidini JN, Doecke CJ, Mansfield PR, Haby MM, Menkes DB, Tonkin AL. Efficacy and safety of antidepressants for children and adolescents. BMJ. 2004;328(7444):879-883.

12. Tsapakis EM, Soldani F, Tondo L, Baldessarini RJ. Efficacy of antidepressants in juvenile depression: meta-analysis. $\mathrm{Br} J$ Psychiatry. 2008;193(1):10-17.

13. Bollini P, Pampallona S, Tibaldi G, Kupelnick B, Munizza C. Effectiveness of antidepressants. Meta-analysis of dose-effect relationships in randomised clinical trials. Br J Psychiatry. 1999;174:297-303.

14. Bech P, Tanghoj P, Andersen HF, Overo K. Citalopram dose-response revisited using an alternative psychometric approach to evaluate clinical effects of four fixed citalopram doses compared to placebo in patients with major depression. Psychopharmacology. 2002;163(1):20-25.

15. Adli M, Baethge C, Heinz A, Langlitz N, Bauer M. Is dose escalation of antidepressants a rational strategy after a medium-dose treatment has failed? A systematic review. Eur Arch Psychiatry Clin Neurosci. 2005; 255(6):387-400.

16. Ruhe HG, Huyser J, Swinkels JA, Schene AH. Dose escalation for insufficient response to standard-dose selective serotonin reuptake inhibitors in major depressive disorder: systematic review. Br J Psychiatry. 2006;189:309-316.

17. Ruhe HG, Booij J, v Weert HC, et al. Evidence why paroxetine dose escalation is not effective in major depressive disorder: a randomized controlled trial with assessment of serotonin transporter occupancy. Neuropsychopharmacology. 2009;34(4):999-1010.

18. Hansen RA, Moore CG, Dusetzina SB, Leinwand BI, Gartlehner G, Gaynes BN. Controlling for drug dose in systematic review and metaanalysis: a case study of the effect of antidepressant dose. Med Decis Making. 2009;29(1):91-103.

19. Quintana H. Transcranial magnetic stimulation in persons younger than the age of 18. JECT. 2005;21(2):88-95.

20. D'Agati D, Bloch Y, Levkovitz Y, Reti I. rTMS for adolescents: safety and efficacy considerations. Psychiatry Res. 2010;177(3):280-285.

21. Croarkin PE, Wall CA, Lee J. Applications of transcranial magnetic stimulation (TMS) in child and adolescent psychiatry. Int Rev Psychiatry. 2011;23(5):445-453.

22. Huang ML, Luo BY, Hu JB, et al. Repetitive transcranial magnetic stimulation in combination with citalopram in young patients with first-episode major depressive disorder: a double-blind, randomized, sham-controlled trial. Aust N Z J Psychiatry. 2012;46(3): 257-264.

23. Mayer G, Aviram S, Walter G, Levkovitz Y, Bloch Y. Longterm follow-up of adolescents with resistant depression treated with repetitive transcranial magnetic stimulation. $J$ ECT. 2012;28(2): $84-86$.

24. Mayer G, Faivel N, Aviram S, Walter G, Bloch Y. Repetitive transcranial magnetic stimulation in depressed adolescents: experience, knowledge, and attitudes of recipients and their parents. J ECT. 2012; 28(2):104-107.
25. Lisanby SH, Luber B, Schlaepfer TE, Sackeim HA. Safety and feasibility of magnetic seizure therapy (MST) in major depression: randomized within-subject comparison with electroconvulsive therapy. Neuropsychopharmacology. 2003;28(10):1852-1865.

26. McClintock SM, Tirmizi O, Chansard M, Husain MM. A systematic review of the neurocognitive effects of magnetic seizure therapy. Int Rev Psychiatry. 2011;23(5):413-423.

27. Wani A, Trevino K, Marnell P, Husain MM. Advances in brain stimulation for depression. Ann Clin Psychiatry. 2013;25(3):217-224.

28. Kayser S, Bewernick BH, Grubert C, Hadrysiewicz BL, Axmacher N, Schlaepfer TE. Antidepressant effects, of magnetic seizure therapy and electroconvulsive therapy, in treatment-resistant depression. J Psychiatr Res. 2011;45(5):569-576.

29. Sackeim HA, Dillingham EM, Prudic J, et al. Effect of concomitant pharmacotherapy on electroconvulsive therapy outcomes: shortterm efficacy and adverse effects. Arch Gen Psychiatry. 2009; 66(7):729-737.

30. Kellner CH, Knapp R, Husain MM, et al. Bifrontal, bitemporal and right unilateral electrode placement in ECT: randomised trial. $\mathrm{Br} \mathrm{J}$ Psychiatry. 2010;196(3):226-234.

31. King MJ, MacDougall AG, Ferris SM, Levine B, MacQueen GM, McKinnon MC. A review of factors that moderate autobiographical memory performance in patients with major depressive disorder. J Clin Exp Neuropsychol. 2010;32(10):1122-1144.

32. Downar J, Geraci J, Salomons TV, et al. Anhedonia and reward-circuit connectivity distinguish nonresponders from responders to dorsomedial prefrontal repetitive transcranial magnetic stimulation in major depression. Biol Psychiatry. 2014;76(3):176-185.

33. Holtzheimer PE 3rd, McDonald WM, Mufti M, et al. Accelerated repetitive transcranial magnetic stimulation for treatment-resistant depression. Depress Anxiety. 2010;27(10):960-963.

34. Baeken C, Marinazzo D, Wu GR, et al. Accelerated HF-rTMS in treatment-resistant unipolar depression: Insights from subgenual anterior cingulate functional connectivity. World J Biol Psychiatry. 2014; 15(4):286-297.

35. Emilien G, Maloteaux JM. Lithium neurotoxicity at low therapeutic doses. Hypotheses for causes and mechanism of action following a retrospective analysis of published case reports. Acta Neurol Belg. 1996; 96(4):281-293.

36. Cusin C, Dougherty DD. Somatic therapies for treatment-resistant depression: ECT, TMS, VNS, DBS. Biol Mood Anxiety Disord. 2012; 2(1): 14 .

37. Blumberger DM, Mulsant BH, Daskalakis ZJ. What is the role of brain stimulation therapies in the treatment of depression? Curr Psychiatry Rep. 2013;15(7):368.

38. Kirov G, Ebmeier KP, Scott AI, et al. Quick recovery of orientation after magnetic seizure therapy for major depressive disorder. $\mathrm{Br} J$ Psychiatry. 2008;193(2):152-155.

39. Semkovska M, Noone M, Carton M, McLoughlin DM. Measuring consistency of autobiographical memory recall in depression. Psychiatry Res. 2012;197(1/2):41-48.

40. Fraser LM, O'Carroll RE, Ebmeier KP. The effect of electroconvulsive therapy on autobiographical memory: a systematic review. JECT. 2008; 24(1):10-17.

41. Verwijk E, Comijs HC, Kok RM, Spaans HP, Stek ML, Scherder EJ. Neurocognitive effects after brief pulse and ultrabrief pulse unilateral electroconvulsive therapy for major depression: a review. $J$ Affect Disord. 2012;140(3):233-243.

42. McElhiney MC, Moody BJ, Steif BL, et al. Autobiographical memory and mood: effects of electroconvulsive therapy. Neuropsychology. 1995;9:501-517.

43. $\mathrm{Ng} \mathrm{C}$, Schweitzer I, Alexopoulos P, et al. Efficacy and cognitive effects of right unilateral electroconvulsive therapy. $J E C T$. 2000;16(4):370-379.

44. McCall WV, Dunn A, Rosenquist PB, Hughes D. Markedly suprathreshold right unilateral ECT versus minimally suprathreshold bilateral ECT: antidepressant and memory effects. J ECT. 2002;18(3): $126-129$. 
45. O’Connor M, Brenninkmeyer C, Morgan A, et al. Relative effects of repetitive transcranial magnetic stimulation and electroconvulsive therapy on mood and memory: a neurocognitive risk-benefit analysis. Cogn Behav Neurol. 2003;16(2):118-127.

46. Loo CK, Sainsbury K, Sheehan P, Lyndon B. A comparison of RUL ultrabrief pulse $(0.3 \mathrm{~ms})$ ECT and standard RUL ECT. Int J Neuropsychopharmacol. 2008;11(7):883-890.
47. Sienaert P, Vansteelandt K, Demyttenaere K, Peuskens J. Randomized comparison of ultra-brief bifrontal and unilateral electroconvulsive therapy for major depression: cognitive side-effects. $J$ Affect Disord. 2010;122(1/2):60-67.

\section{Publish your work in this journal}

Neuropsychiatric Disease and Treatment is an international, peerreviewed journal of clinical therapeutics and pharmacology focusing on concise rapid reporting of clinical or pre-clinical studies on a range of neuropsychiatric and neurological disorders. This journal is indexed on PubMed Central, the 'PsycINFO' database and CAS, and is the official journal of The International Neuropsychiatric Association (INA). The manuscript management system is completely online and includes a very quick and fair peer-review system, which is all easy to use. Visit http://www.dovepress.com/testimonials.php to read real quotes from published authors.

Submit your manuscript here: http://www.dovepress.com/neuropsychiatric-disease-and-treatment-journal 